\title{
Implicit Versus Explicit Feedback in Classroom: An Experimental Study
}

\author{
Zahra Rastegar Haghighi Shirazi \\ Department of Foreign Languages, Marvdasht Branch, Islamic Azad University, Marvdasht, Iran \\ Email: zrastegar@gmail.com \\ Firooz Sadighi \\ Department of Foreign Languages, Shiraz Branch, Islamic Azad University, Shiraz, Iran
}

\begin{abstract}
The quasi-experimental design used in this study aimed at investigating the merits of using two types of corrective feedback, namely recasts and elicitations. Sixty EFL learners were randomly assigned to three groups (recast, elicitation and control group). The instructional intervention targeted the relative clauses. Acquisition was measured by a grammaticality judgment test. The results proved that the experimental groups significantly outperformed the control group. Besides, the results of the one-way ANOVA indicated the greater effectiveness of elicitations in posttest to recast group. However, the results of delayed post test showed no significant differences between the two treatment groups.
\end{abstract}

Index Terms - corrective feedback, explicit feedback, implicit feedback, recasts, elicitations

\section{INTRODUCTION}

Since its inception, interaction hypothesis has greatly raised our consciousness of the tremendous effects of interlocutor's feedback on the learner's language development. This hypothesis is based on the premise that negotiation for meaning facilitates acquisition. The corrective feedback (CF) resulting from negotiation of meaning is beneficial to and facilitative of L2 development. It sets the stage for learner to focus on some aspects of language which will subsequently lead to incidental, implicit language learning (Long, 1996). In addition, the role of CF has been acknowledged by Schmidt's (1990, 2001) Noticing Hypothesis which states that second language acquisition is derived by the learners' attention to input. From this perspective, $\mathrm{CF}$ serves as a trigger for noticing.

The rise of research in the area of $\mathrm{CF}$ over the past decade reflects a growing recognition of the paramount role of this issue in language leaning. There have been some descriptive studies focusing on the teachers' and learners' preferences for error correction methods (Firwana, 2010; Halimi, 2008; Park, 2010), experimental studies examining different features of feedback such as the degree of explicitness (Doughty and Varela, 1998;Takahashi, 2007), or linguistic targets, length, number of changes ( Egi, 2007), and the effectiveness of different types of CF (Ammar and Spada, 2006; Ellis, Loewen, Erlham 2006; Nassaji, 2009; Perdomo, 2008).

Given the body of research on beneficial effects CF in developing the learners' competence, the present study seeks to determine the differential effects of recasts and elicitation.

\section{REVIEW OF LITERATURE}

CF has been defined by Lightbown and Spada (1999) as "any indication to the learners that their use of the target language is incorrect" (p. 171). CF research "constitutes an area of inquiry that can connect theory, research and practice" (Sheen, 2010, p.177). Different researchers have adopted various categorizations of CF but most have employed a combination of the six types which were proposed by Lyster and Ranta (1997): recasts, explicit correction, clarification requests, metalinguistic feedback, elicitation, and repetition. Two of the most important categories recast as an implicit feedback and elicitation as an explicit have been considered in this study.

\section{A. RECASTS}

More than any other type of CF, recasts have attracted the attention of many researchers (Ellis and Sheen, 2006; Hawkes, 2003) and it seems to have been the most influential type of feedback (Ayoun, 2001; Long, Inagaky and Ortega, 1998). The main motive behind this is the fact that in different classrooms recast is the most frequent negative feedback type used by language teachers (Lochtman 2002 cited in Ellis and Sheen, 2006; Lyster, 1998a; Lyster and Ranta, 1997; Nassaji, 2007; Panova and Lyster, 2002). Moreover, recasts have been distinguished from other feedback types based on the premise that they are not explicit and don't interrupt the flow of communication (Baleghizadeh and Abdi, 2010).

In the context of first language, recasts are viewed as "utterances in which the caretaker produces an expanded grammatically correct version of a prior child utterance" (Mitchell and Myles, 2004, p. 162). For L2, Lyster and Ranta 
(1997) define recast as "the teacher's reformulation of all or part of a student's utterance, minus the error" (p. 46). Long (2007) considers recast as the reformulation of a learner's utterance in which one or more non target like items are exchanged with the correct target like item. He further adds that during recast, the focus of the interlocutor is on exchanging communicative information and not treating language as an object. Recast neither damages the learners' self-confidence (Loewen and Philp, 2006) nor does it "intrude unduly in the communicative flow of the activity". It constitutes a brief time-out from communicating, which allows the learner to focus explicitly but briefly on form" (Ellis, Loewen, Erlam, 2006, p. 363).

Recasts not only provide positive evidence but also negative one, enhance interaction, and make the target forms more salient (Hawkes, 2003). They arise from a communicative language development in which both parties share "a joint intentional focus" (Long, 2007, p.114).

Despite the obvious merits of recasts, there are some drawbacks. First, they are not usually followed by self- or peerrepair. In other words, students only repeat the teachers' correct formulation of their utterances (Baleghizadeh and Abdi, 2010). In addition, since recasts do not provide any explicit indication of errors (Ellis, 2007) they are assumed to be ambiguous by some researchers because they are difficult to distinguish from non-corrective repetition. They might be considered as confirmation, paraphrase or a CF (Lyster, 1998a). In fact, some argue that "recasts of grammatical errors probably do not provide young classroom learners with negative evidence, in that they fail to convey what is unacceptable in the L2" (Lyster, 1998b, p. 207).

\section{B. Ellicitation}

Elicitation as another type of feedback has been defined as a feedback type in which the learner is not provided with the reformulated utterance, rather he is pushed toward self-correction (Lyster and Mori, 2006). Lyster (1998b) proposes that this process of self-correction necessitates a deeper processing level and is therefore more effective in enhancing the learners' language knowledge. Pausing, encouraging students to self reformulate, asking questions are the three techniques proposed by Lyster and Ranta (1997).

\section{Empirical Studies on Corrective Feedback}

Experimental and quasi experimental designs of studies have been utilized to investigate the effectiveness of various types of CF. To investigate the effectiveness of corrective recasting, Doughty and Varela (1998) compared the performance of two groups of young learners in a content-based classroom. The results showed that the learners in the corrective recasting group which included a repetition of the error, followed by a recast outperformed the other group who received no feedback.

In a similar vein, Han (2002) examined the contribution of CF in the form of recast to the acquisition of tense consistency. He found out that due to their heightened awareness, the learners in the recast group were more successful in both oral and written tests in comparison to the no feedback group. In their experimental design study, Ellis, Loewen and Erlam (2006) compared the effectiveness of implicit and explicit CF on low-intermediate learners' performance. To measure the implicit knowledge, an oral imitation test was employed while in order to tap into the learners' explicit knowledge, an untimed grammaticality judgment test in addition to a metalinguistic knowledge test were used. The statistical analysis indicated the superiority of explicit feedback over the implicit type for both delayed imitation and grammaticality judgment test.

Lyster (2004) investigated the differential effects of recasts and prompts for the acquisition of grammatical gender in French. The different prompts included in his study were elicitations, metalinguistic cues, clarification requests, and repetitions. The results indicated that prompts combined with form-focused instructions were much more effective than formed-focused classroom receiving recasts. Similar results were reported by Panova and Lyster (2002).

Peredomo (2006) examined the effectiveness of two feedback types on the learners' acquisition of auxiliary verb 'to have' and the use of past participle in the present perfect tense. The participants were randomly divided into two distinct feedback type groups (recast and explicit negative evidence). Interestingly, the learners in the recast group outperformed the other group who were provided with explicit negative evidence.

Believing that focus on form instruction is very effective in L2 learning, Menti (2003) aimed at exploring the effects of recast and elicitation on the performance of intermediate EFL learners in a private language institute. The results of immediate post- test showed that the elicitation group created less erroneous sentences.

Ammar (2003) conducted a quasi-experimental design study to discover the potential effectiveness of two different negative feedback techniques, namely elicitation and recast. The participants were two groups of low proficient and high proficient learners. The targeted structure was possessive determiners. They designed a pre-test, immediate post test and a delayed post test. The statistical analysis showed that the high proficiency group took equal advantage of both elicitation and recast while the low proficiency learners profited more from elicitations on both immediate and delayed post test.

In their fully controlled study, Carroll and Swain (1993) probed into the effects of 4 different types of negative feedback on L2 acquisition. They specifically aimed at determining whether CF could teach learners the appropriate constraint on a generalized rule. To this end, one hundred subjects were randomly assigned to 4 experimental groups and a control group. While the first group simply was told that their sentence was erroneous, the other experimental groups received explicit error correction, recast, metalinguistic feedback. Analysis of data proved the superiority of all 4 
groups in comparison to the no feedback group. Besides, the metalinguistic feedback proved to enhance the learners' competence to a greater extent than other feedback types.

Not only have researchers investigated the role of error correction and the comparison of its various types, but also they have examined the cognitive processes occurring in the language learning process. As an example, Nabeu and Swain (2002) performing a case study on a 19 year old EFL learner, they aimed at scrutinizing the relationship between the learner's awareness of recast and 12 learning. The results demonstrated that recasting as a complex verbal behavior is impacted by some factors as the teaching atmosphere, interaction context, and the learners' cognitive styles. Furthermore, the results demonstrated that recast is not only manipulated by feedback type (grammatical and lexical), but also by paralinguistic factors as well as the learner's potentials for taking advantages of the learning opportunities provided by feedback.

Carroll and Swain (1993) and DeKesyer (1993) state that most studies on CF have not isolated formal instruction from $\mathrm{CF}$ and therefore, their results might have been biased by the formal instruction. Studies like Ammar and Spada (2006) and Lyster (2004) are two examples of such claim. Therefore, the present study aims at filling this gap.

\section{RESEARCH QUESTIONS}

1. Do the learners who are exposed to communicative activities including a CF benefit more than those who are just exposed to communicative activities?

2. Is explicit negative feedback in the form of elicitations more effective than implicit feedback in the form of recasts?

\section{METHOD}

The present study adopted a quasi-experimental design involving a pre-test, treatment and two tests (a post test, and a delayed post test).

\section{A. Participants}

Sixty students participated in this study. All participants except one were monolingual. The mean age of participants was 23. The study was conducted at an Institute in Shiraz. Based on the result of a TOEFL test, they were considered to be intermediate learners. Learners at this proficiency level were assumed to be appropriate because they could maintain communicative interactions and their errors could be amenable to CF. The teaching approach adopted by the Institute was the communicative one. Students attended the class twice a weak each for 2 hours.

\section{B. Procedure}

A TOEFL test was administered in order to ensure the homogeneity of the group. Out of the total of 75 students who participated in this study, 60 students were included in the study because of their different level of proficiency. They were assigned to intact groups (two experimental groups and a control group). The learners in the treatment group were asked to perform some communicative focused task (Ellis, 2003) in three successive sessions. The tasks purposefully elicited the relative clauses. The two experimental groups received feedback either in the form of recasts or elicitations while the control group neither completed these tasks nor did it receive any feedback. The learners in this group just continued their usual instruction.

\section{Target Structure}

In this study, intensive feedback focusing on just some pre-selected target forms were used. Relative clause was adopted as the target structure for the following main reasons: first because learners had already learned this structure and second based on our many years of teaching experience relative clause is one of the most problematic structures for Iranian learners. Either the relative clause is erroneously produced or as Pazhakhi (2007) envisions it the learners avoid it by simply mixing two simple sentences. This is further supported by the contrastive analysis of Persian and English as well as previous research by Schachter (1974) which has demonstrated that relative clauses are one of the most difficult structures for Iranian learners to acquire. The third reason for choosing this structure related to its paramount role in interactional communication.

The typical errors made by learners were the following types:

*The man that he is wearing a jacket is my father.

*This is the book that I borrowed it.

*The man who his shirt is blue is my father.

*The man that is driving is energetic.

*These are the people that she knows their neighbors.

Or they might totally avoid the relative pronoun by producing sentences like the following:

I met the woman. She is a doctor.

Our aim in this study was not examining whether CF can help learners in acquiring completely brand new structures, but whether or not it can assist the learners in gaining more control over the structure that they already know.

\section{Instructional Material}


Various picture description tasks which were of focused type (Ellis, 2003) were utilized. The main focus of the task was on meaning, not form. The learners were asked to imagine that they were on the phone with a friend who really needed to know the information in the pictures; So they were to describe the information in the picture using relative pronouns (whose, whom, where, which, who, when, etc.). In addition, they were to imagine themselves describing a criminal scene for a detective. Each instructional treatment session took 30 to 45 minutes. The teacher in the recast group reformulated the learners' mistakes while she tried to elicit the correct response in the other treatment group.

Examples of recasts and elicitations provided to learners:

Recast:

Sara: the man whom I saw him was tall.

Teacher: the man whom I saw was tall.

Elicitation:

Parisa: the girl that was wearing a yellow dress was tall

Teacher: Say that again please.

The girl.

Pardon me!

\section{E. Measurements}

Three completely similar tests were designed. A pretest, a post test, and a delayed post test were conducted in a counter-balanced design as proposed by Brown (1988) to reduce test-retest effects. Initially a pilot study was undertaken on the tests and after the subsequent item analysis, the best functioning items were chosen and the rest were either eliminated or modified. Each test included 40 items (20 correct, 20 incorrect) in addition to the 10 distracters. The reliability index of the tests was established through Cronbach Alpha. The reliability of the three tests computed through Cronbach Alpha was .78, .82, and .79 consecutively. The students sat for the pretest a day before the treatment, the post test, a day after the treatment activities, and the delayed post test, 15 days after the posttest.

\section{DATA ANALYSIS}

Using SPSS 16, descriptive statistics were calculated. Then one-way ANOVA was run on the raw scores of the grammaticality judgment tests (pre-test, post-test, delayed post test) to check significant differences between the two groups. Post hoc analysis was respectively performed when the results of ANOVA deemed significant.

\section{RESUlts}

The descriptive statistics are presented in Table 1.

TABLE 1

DESCRIPTIVE STATISTICS FOR TEST SCORES BY GROUP

\begin{tabular}{lllllll}
\hline \hline Group & & $\mathrm{N}$ & Minimum & Maximum & Mean & Std. Deviation \\
\hline 1 & A & 20 & 17.00 & 32.00 & 24.4500 & 4.45415 \\
& B & 20 & 17.00 & 30.00 & 23.8000 & 3.99473 \\
& C & 20 & 15.00 & 32.00 & 23.9000 & 4.80022 \\
& & & & & & \\
\hline 2 & A & 20 & 17.00 & 29.00 & 24.3000 & 3.68639 \\
& B & 20 & 22.00 & 30.00 & 26.2500 & 2.38140 \\
& C & 20 & 21.00 & 34.00 & 27.2000 & 3.95501 \\
& & & & & \\
\hline 3 & A & 20 & 17.00 & 30.00 & 24.6000 & 3.51538 \\
& B & 20 & 23.00 & 34.00 & 28.8000 & 3.05390 \\
& C & 20 & 20.00 & 33.00 & 28.1500 & 3.29713 \\
& & & & & \\
\hline \hline
\end{tabular}

The three groups showed uniformity in their knowledge of relative clauses at the time of pre-test. To further investigate the differences among the three groups, a one-way ANOVA was computed. 
TABLE 2

THE ONE WAY ANOVA

\begin{tabular}{lllllll}
\hline \hline & & Sum of Squares & df & Mean Square & F & Sig. \\
\hline A & Between Groups & .900 & 2 & .450 & .029 & .971 \\
& Within Groups & 869.950 & 57 & 15.262 & & \\
& Total & 870.850 & 59 & & 12.116 & .000 \\
\hline B & Between Groups & 250.033 & 2 & 125.017 & 10.318 & \\
& Within Groups & 588.150 & 57 & & \\
& Total & 838.183 & 59 & & \\
& Between Groups & 199.033 & 2 & 99.517 & & .004 \\
& Within Groups & 941.550 & 57 & 16.518 & & \\
& Total & 1140.583 & 59 & & & \\
& & & & & & \\
\end{tabular}

The ANOVA run on the pre-test shows that there was no significant differences among the three groups in terms of their overall performance, $F(2,57)=.029, P=.97$. However, the groups receiving feedback performed considerably different from the non-feedback group in both post test and delayed post test. $\mathrm{F}(2,57)=12.11, \mathrm{P}=.00$ for the post test, and $\mathrm{F}(2,57)=6.07, \mathrm{P}=.00$ for the delayed post test. Post hoc Tukey pairwise comparisons indicated that the treatment groups (recasts and elicitations) outperformed the control group in both post test and delayed post test. So the first research question was answered affirmatively.

As for the feedback type, the results of one-way ANOVA showed that the difference between the two experimental groups was significant. Post hoc Tukey comparisons indicated that the elicitation feedback in the immediate post-test was significantly superior to the recast type of feedback $(\mathrm{p}=.03)$. However, the difference between the two experimental groups did not reach statistical significance $(\mathrm{p}=.74)$ in the delayed post test.

\section{DISCUSSION AND CONCLUSION}

This study aimed at examining the effects of CF in L2 learning. Besides, it sought to explore the effects of implicit and explicit feedback. The explicit feedback was operationalized as elicitations while implicit feedback as recasts. The results of the post test and delayed post test empirically supported the fact that exposing learners to communicative activities in juxtaposition with consciousness raising activities such as error correction is more effective than exposing them to mere communicative activities. This is in line with empirical findings of Carroll and Swain (1993); Doughty and Varela (1998); Lightbown and Spada (1999); Leeman (2003); Muranoi (2000); and White (1991) comparing feedback and no feedback group. So this will shed light on the importance of teachers' error correction of the learners to produce target like structures.

Concerning the differential effects of elicitations and recasts, the results of the immediate post-test demonstrated the superiority of the elicitations in comparison to recasts which can be accounted for by taking into consideration the explicit-implicit dichotomy. Explicit feedback led to much more feedback appreciation. Thus, this study provided empirical support for negative evidence especially the explicit type of feedback. this will subsequently corroborate Schmidt's (2001) noticing hypothesis which emphasizes attracting the learners' attention to formal aspects of language in order to achieve linguistic gains.

The justification behind the less effectiveness of recast was the fact that the learners couldn't notice the teachers' reformulation as a kind of CF; rather they might have assumed it as a mere positive evidence. In this regard, Long (1996) asserted, "The fact that an utterance is intended as a correction . . . does not necessarily mean that a learner will perceive it that way" (p. 432). Therefore, they might have considered it as a confirmation of their utterance than a reformulation and correction of it.

As for the delayed post test, although still greater gains were achieved by the elicitation group, no significant difference was observed between the two types of CF. In other words, although greater achievements were gained through explicit feedback, it didn't prove to be significantly different from the implicit one. This can imply the more enduring nature of recast which is also corroborated by Rassaei and Moinzadeh (2011).

\section{PEDAGOGICAL IMPLICATIONS}

The most important goal of teachers is enhancing teaching. One of the most salient ways to achieve this goal is through error correction. Using more form focused activities in combination with meaning based activities deems beneficial; Learners should be provided with more opportunities to interact more with competent interlocutor to receive $\mathrm{CF}$ in its various forms. However, rather than choosing one type of feedback, teachers should have a variety of different feedback types at their disposal to choose from.

Based on the findings of this study, one might be tempted to conclude that explicit feedback is always better than the implicit one. However, special care must be exercised when choosing a particular feedback type since factors such as 
context, level of proficiency (Amar and Spada, 2006; Perdomo, 2008; Rodriguez and Perdomo, 2002), type of the target structure, learners' orientation toward a particular feedback, age, motivation and many other factors (Nassaji, 2006) can affect the outcome of a particular type of feedback. Teachers, therefore, need "to orchestrate, in accordance with their students' language abilities and content familiarity, a wide range of feedback types befitting of the instructional context" (Lyster, 2007, p. 124).

Another pedagogical implication of this study is the need to promote the saliency of recast to decrease its ambiguity and add to its beneficial value as a common feedback type in English classes. In this regard, some researchers have put forward the idea that recasts are likely to be more useful if highlighted by clues so that learners can perceive them as CF rather than as a communicative response to what they said (Nicholas, Lightbown, and Spada, 2001; Takahashi, 2007).

\section{REFERENCES}

[1] Ammar, A. (2003). Corrective feedback and 12 learning: Elicitation and recasts. Unpublished doctoral dissertation, Mc Gill University, Montreal.

[2] Ammar, A. \& Spada, N. (2006). One size fits all? Recasts, Prompts and language learning. Studies in Language Learning, 28, 543-574.

[3] Ayoun, D. (2001). The role of negative feedback in the second language acquisition of the passé compose and imparfait. Modern Language Journal, 85(2), 226-243.

[4] Baleghizadeh, S. \& Abdi, H. (2010). Recast and Its Impact on Second Language Acquisition. International Journal of Language Studies, 4( 4), 301-312.

[5] Brown, J. D. (1988). Understanding research in second language learning: A teacher's guide to statistics and research design. London: Cambridge University Press.

[6] Carroll, S., \& Swain, M. (1993). Explicit and implicit negative feedback: An empirical study of the learning of linguistic generalizations. Studies in Second Language Acquisition, 15, 357- 386.

[7] DeKeyser, R. (1993). The effect of error correction on L2 grammar knowledge and oral proficiency. Modern Language Journal, 77, 501-514.

[8] Doughty, C. \& Varela, E. (1998). Communicative focus on form. In C. Doughty \& J. Williams (Eds.), Focus on Form in classroom second language acquisition (pp. 114-138). New York: Cambridge University Press.

[9] Egi, T. (2007). Interpreting recasts as linguistic evidence: The roles of linguistic target, length, and degree of change, Studies of Second Language Acquisition, 29 (4), 511-537.

[10] Ellis, R (2003). Task-based language learning and teaching, Oxford: Oxford University Press.

[11] Ellis, R. (2007). The differential effects of corrective feedback on two grammatical structures. In A. Mackey (Ed.), Conversational interactionin second language acquisition (pp. 339-360). Oxford University Press.

[12] Ellis, R., Loewen, S. \& Erlam, R. (2006). Implicit and explicit corrective feedback and the acquisition of L2 grammar. Studies in Second Language Acquisition, 28 (2), 339-368.

[13] Ellis, R. \& Sheen, Y. (2006). Reexamining the role of recasts in second language acquisition, 28, 575-600.

[14] Firwana, S.S. (2010). Impact of Palestinian EFL teachers' attitudes toward oral error on their students' attitudes and choice of error treatment strategies. Unpublished doctoral dissertation, Boston College, Lynch School of Education.

[15] Halimi, S. S. (2008). Indonesian teachers' and students' preferences for error correction. Wacana, 10 (1), 50-71.

[16] Han, Z (2002). A study of the impact of recasts on tense consistency in L2 output. TESOL Quarterly, 36, 543-572.

[17] Hawkes, L. (2003). Recasts revisited: The role of recasts in error detection and correction by adult ESL students. MA thesis. Queen's University at Kingston.

[18] Leeman, J. (2003). Recasts and second language development: Beyond negative evidence, Studies in Second Language Acquisition, 25, 37-63.

[19] Lightbown, P. \& Spada, N. (1999). How Languages are learned. Oxford: Oxford University Press.

[20] Lochtman, K. (2002). Oral corrective feedback in the foreign language classroom: How it affects interaction in analytic foreign language teaching. International Journal of Educational Research, 37, 271-83.

[21] Loewen \& Philip, (2006). Recasts in the adult English L2 classroom: characteristics, explicitness, and effectiveness. The Modern Language Journal, 90, (4), 536-556.

[22] Long, M. (1996). The role of the linguistic environment in second language acquisition. In W. C. Ritchie \& T. K. Bhatia (Eds.), Handbook of language acquisition: Vol.2. Second language acquisition (pp.413-468). San Diego, CA: Academic Press.

[23] Long, M. (2006). Problems in SLA. Mahwah, NJ: Erlbaum.

[24] Long, M. (2007). Problems in SLA. Mahwah, NJ: Lawrence Erlbaum.

[25] Long, M., Inagaky, S. \& Ortega, L. (1998). The role of implicit negative feedback in SLA: Models and recast in Japanese and Spanish. The Modern Language Journal, 82( 3), 357-371.

[26] Lyster, R. (1998a). Recasts, repetition, and ambiguity in L2 classroom discourse. Studies in Second Language Acquisition, 20, 51-81.

[27] Lyster, R. (1998b). Negotiation of form, recasts, and explicit correction in relation to error types and learner repair in immersion classrooms Language Learning, 48, 183-218.

[28] Lyster, R. (2004). Differential effects of prompts and recasts in form-focused instruction. Studies in Second Language Acquisition, 26 (3), 399-432.

[29] Lyster, R. (2007). Learning and teaching languages through content: A counterbalanced approach. Amsterdam: Benjamins.

[30] Lyster, R., \& Mori, H. (2006). Interactional feedback and instructional counterbalance. Studies in Second Language Acquisition, $28,269-300$.

[31] Lyster, R. \& Ranta, L. (1997). Corrective feedback and learner uptake: Negotiation of form in communicative classrooms. Studies in Second Language Acquisition, 19, 37-66. 
[32] Menti, M. M. (2003). Efeito de dois tipos de feedback corretivo - recast e elicitação - no desempenho de alunos de inglês como língua estrangeira. Dissertação de Mestrado. PPG/Letras da Universidade Federal do Rio Grande do Sul.

[33] Muranoi, H. (2000). Focus on form through interaction enhancement: Integrating formal instruction into a communicative task in EFL classrooms, Language Learning, 50, 617-673.

[34] Mitchell, R., \& Myles, F. (2004). Second language learning theories. (2nd ed.). London: Hodder Arnold.

[35] Panova, I., \& Lyster, R. (2002). Patterns of corrective feedback and uptake in an adult ESL classroom. TESOL Quarterly, 36, 573-95.

[36] Nabei, T. \& Swain, M. (2002). Learner Awareness of Recasts in Classroom Interaction: A Case Study of an Adult EFL Student's Second Language Learning. Language Awareness 11, 1, 43.

[37] Nassaji, H. (2006). Elicitation and reformulation and their relationship. Language learning, 57 (4), 511-548.

[38] Nassaji, H. (2007). Elicitation and reformulation and their relationship with learner repair in dyadic interaction. Language Learning, 57, 511-548.

[39] Nassaji, H. (2009). Effects of recasts and elicitation in Dyadic Interaction and the role of feedback explicitness, Language Learning, 59, (2), 411-452.

[40] Nicholas, H., Lightbown, P., \& Spada, N. (2001). Recasts as feedback to language learners. Language Learning , 51, $719-758$.

[41] Panova, I., \& Lyster, R. (2002). Patterns of corrective feedback and uptake in an adult ESL classroom. TESOL Quarterly, 36, 573-595.

[42] Park, H.S. (2010). Teachers' and learners' preferences for error correction, Unpublished MA Thesis, California State University, Sacramento.

[43] Pazhakhi, A. (2007). An Investigation on Iranian EFL Learners' Application of Avoidance Strategies in Their Writings. Iranian Journal of language studies, 1 (1), 1-14.

[44] Perdomo, B. ( 2008). Effectiveness of Recasts in the Teaching of EFL. The Asian EFL Journal, 10 ( 2), 155.

[45] Rassaei, E. \& Moinzadeh, A. (2011). Investigating the effects of three types of corrective feedback on the acquisition of English wh-forms by Iranian EFL learners, English Language Teaching, 4 (2), 97-105.

[46] Rodríguez, M. \& Perdomo, B. (2002). Effects of Implicit and Explicit Negative Feedback on EFL Students' Oral Performance. Paper presented at the annual TESOL convention, VenTESOL, Nueva Esparta, Venezuela.

[47] Schachter, J. (1974). 'An error in error analysis'. Language Learning, 24, 205-214.

[48] Schmidt, R. (1990). The role of consciousness in second language learning. Applied Linguistics 11(2), 129-58.

[49] Schmidt, (2001). Attention. In P. Robinson (Eds.), Cognition and second language instruction (pp. 3-32). New York, Cambridge University Press.

[50] Sheen, Y. (2010). The role of oral and written corrective feedback on SLA. Studies in Second Language Acquisition, 32, 169179.

[51] Takahashi, N. (2007). The differential effects of perceptual saliency on recasts in L2 Japanese learners' noticing, interpretation, detection, and subsequent oral production, Unpublished Ph.D Dissertation, University of Iowa.

[52] White, L. (1991). Adverb placement in second language acquisition. Some positive and negative evidence in the classroom. Second Language Research, 7, 133-161.

Zahra Rastegar Haghighi Shirazi is a Ph.D candidate at Shiraz Azad University and a lecturer at Islamic Azad University, Marvdasht Branch. Her areas of interests are language teaching, testing and assessment, and CALL.

Firooz Sadighi is Professor of English language and linguistics at Shiraz University. He received his doctor of philosophy from the University of Illinois at Urbana-Champaign, USA in 1982. He has taught syntax, psycholinguistics, first language acquisition, second language acquisition, and syntactic argumentation in the Ph.D. program in TEFL. His research areas are foreign language learning/ L2 acquisition, linguistics: syntax, semantics, and phonology, psycholinguistics and syntactic argumentation. 